\title{
Knuckle Pads - Practical Diagnostic Issues
}

\author{
Anca Chiriac $1,2,3$, Piotr Brzezinski ${ }^{4}$ Liliana Foia ${ }^{5}$, Cristian Podoleanu ${ }^{6}$, Cosmin Moldovan $^{7}$, \\ Simona Stolnicu 8,9 \\ ${ }^{1}$ Apollonia University, Department of Dermatology, lași, Romania \\ 2 "Petru Poni" Institute of Macromolecular Chemistry of the Romanian Academy, Iași, Romania \\ 3 Nicolina Medical Center, Iași, Romania \\ 4 6th Military Support Unit, Utska, Poland \\ 5 "Gr.T. Popa” University of Medicine and Pharmacy, lași, Romania \\ 6 Department of Internal Medicine, University of Medicine and Pharmacy, Tîrgu Mureș, Romania \\ 7 Department of Medical Simulation, University of Medicine and Pharmacy, Tîrgu Mureș, Romania \\ 8 Department of Pathology, University of Medicine and Pharmacy, Tîrgu Mureș, Romania \\ 9 Histopat Invest Laboratory, Tîrgu Mureș, Romania
}

\section{CORRESPONDENCE}

\section{Cristian Podoleanu}

Str. Gheorghe Marinescu nr. 38

540099 Tîrgu Mureș, Romania

Tel: +40 744573784

E-mail: podoleanu@me.com

\section{ARTICLE HISTORY}

Received: 19 April, 2017

Accepted: 25 May, 2017

Anca Chiriac • Str Muzicii nr. 2, 700399 lași, Romania Tel: +40 232210310

Piotr Brzezinski • Department of Dermatology, 6th Military Support Unit, os. Ledowo 1N, 76-270 Ustka, Poland. Tel: +48692121516

Liliana Foia • Str. Universitătii nr. 16, 700115 lași, Romania. Tel: +40 232267801

Cosmin Moldovan • Str. Gheorghe Marinescu nr. 38 540139 Tîrgu Mureș, Romania. Tel: +40 265215551

Simona Stolnicu • Str. Gheorghe Marinescu nr. 38

540139 Tîrgu Mureș, Romania. Tel: +40 265215551

\begin{abstract}
Knuckle pads are thickening of the skin over the extensor surface of the proximal interphalangeal joints. Clinical picture, ultrasound imaging, and histopathological examination of the skin biopsy ascertain the diagnosis. In routine practice, two main differential diagnoses are important: knuckle pads vs. pseudo-knuckle pads and idiopathic vs. non-idiopathic forms of knuckle pads.
\end{abstract}

Keywords: skin, elderly, finger joints, pseudo-knuckle pads

\section{INTRODUCTION}

Knuckle pads are described as thickening of the skin over the extensor surface of the finger joints. The first report of this condition was published by Garrod in 1893; since then, not many cases have been published, probably due to misdiagnosis or the lack of recognition of the asymptomatic lesions over small joints, the condition being more prevalent in the elderly. ${ }^{1}$

The lesion has been previously known under the terms of benign fibroma over the small joints of the hands and feet, helodermia, keratosis supracapitularis, pulvinus or subcutaneous fibroma; however, the term currently used for this lesion is knuckle pads. ${ }^{2}$

Being a benign fibroma, the lesion has been associated with a number of other fibrosing disorders such as Dupuytren's contracture, Ledderhose's syndrome, and Peyronie's disease. ${ }^{3}$ Knuckle pads and finger pebbles (cobblestone appearance of the skin on the dorsum of the digits) are common findings in diabetes mellitus, especially in elderly with type 2 diabetes. ${ }^{4}$

Knuckle pads are represented by asymptomatic thickened, colored, mobile skin plaques or nodules located over the small joints of the hands, symmetri- 

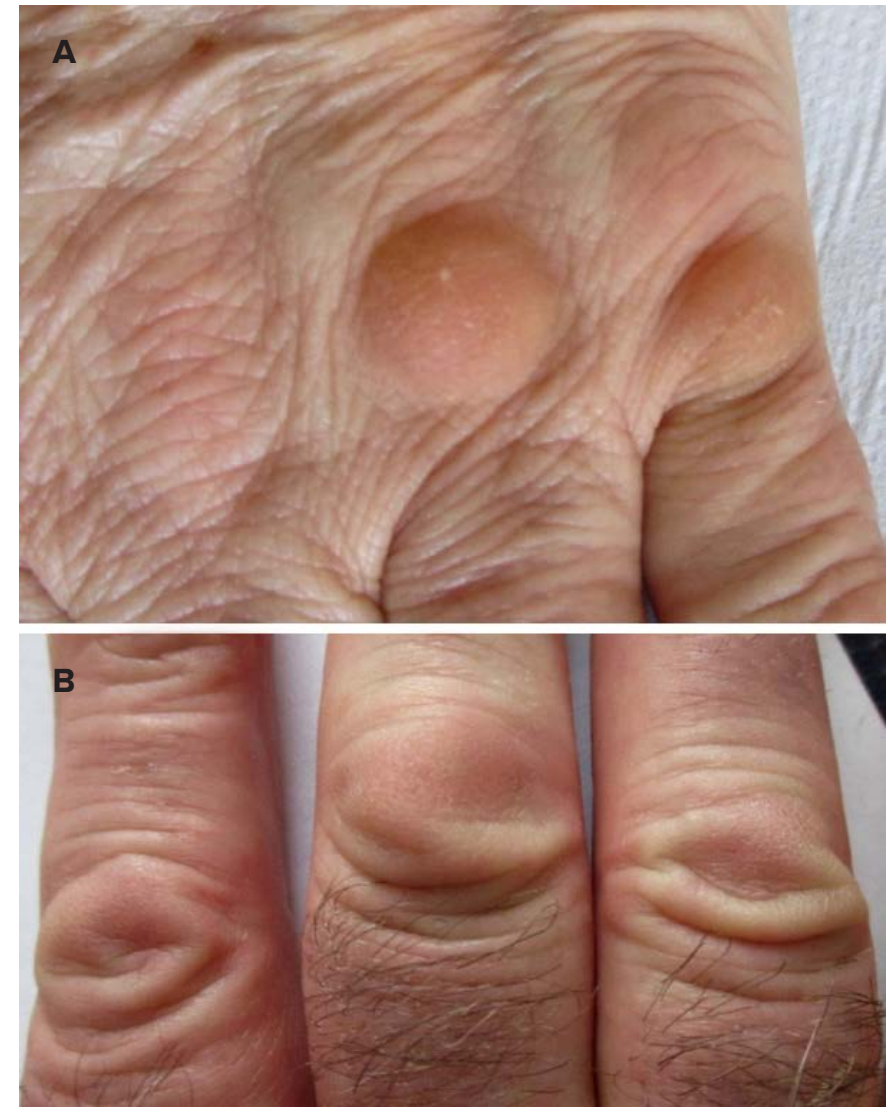

FIGURE 1. A - Well-circumscribed thickening of the skin over the extensor surface of the dorsal aspect of the metacarpophalangeal joints (knuckle pads); $\mathbf{B}$ - thickening of the skin on the interphalangeal joints ("diabetic finger pebbles")

cally distributed over almost all digits (Figure $1 \mathrm{~A}, \mathrm{~B}$ ). Knuckle pads have been described mostly in men, in the

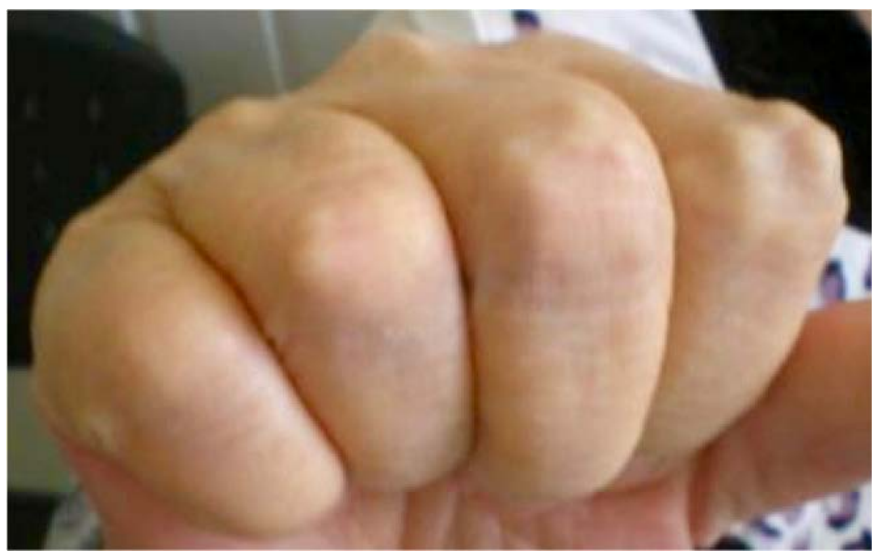

FIGURE 2. Gouty tophi - whitish-yellow, small nodules on the interphalangeal and metacarpophalangeal joints, extruding chalky material

third to fifth decades of life or even later. ${ }^{5}$ The lesions are located on the dorsal aspect of the metacarpophalangeal and interphalangeal joints; they are symptom-free and have a chronic evolution. A close correlation between metabolic syndromes, especially abdominal obesity and hypertension, with or without type 2 diabetes, and the presence of knuckle pads has been found, underlining the importance of close monitoring of patients with knuckle pads. ${ }^{6,7}$

\section{DIFFERENTIAL DIAGNOSIS}

The differential diagnosis of knuckle pads should include gouty tophi, which present as painful, soft, whitish-yellow, small nodules affecting mainly the distal interpha-

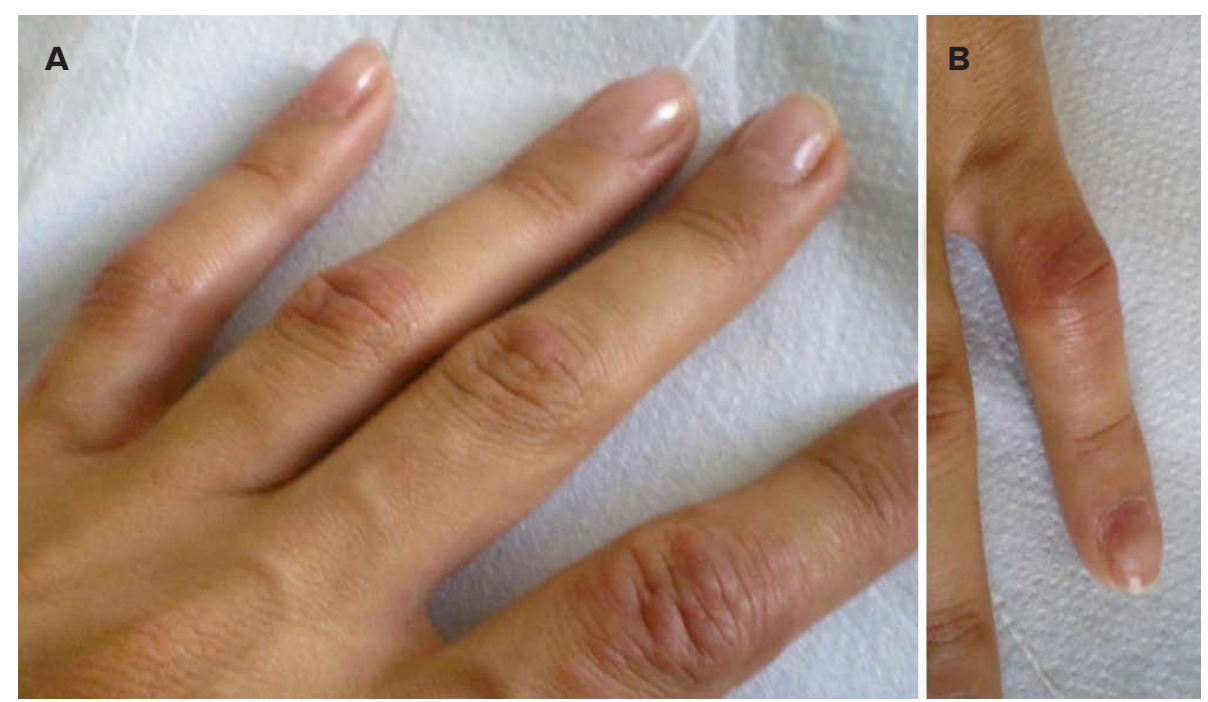

FIGURE 3. Rheumatoid nodules - subcutaneous nodules in patients with rheumatoid arthritis (A, B) 


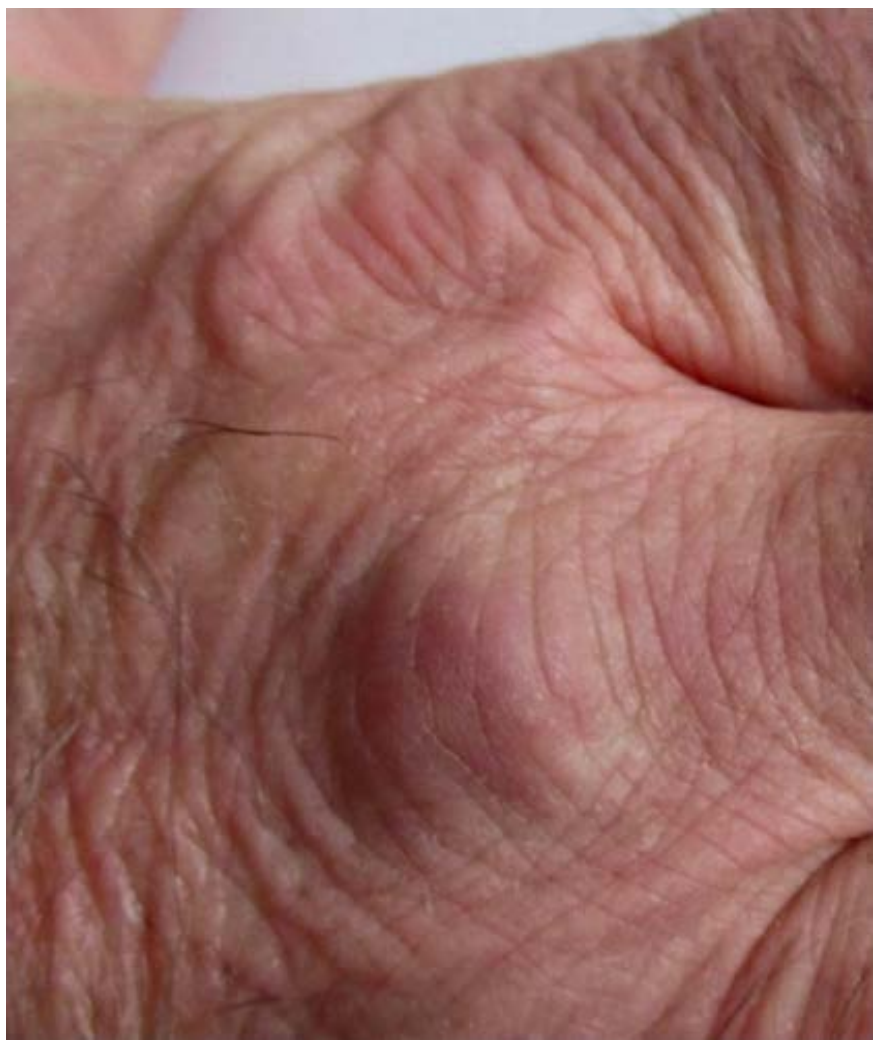

FIGURE 4. Foreign body granuloma - inflammatory nodule on the dorsal aspect of the metacarpophalangeal joint of the third right digit

langeal joints, the dorsal aspect of the proximal interphalangeal and metacarpophalangeal joints; often the lesions extrude a white, chalky material (Figure 2). Rheumatoid nodules are well-demarcated, mobile, firm, asymptomatic subcutaneous nodules on the extensor surfaces of the elbows and fingers, occurring in patients with rheumatoid arthritis (Figure 3). Other diagnoses that are to be excluded include: foreign body granulomas, represented by a solitary inflammatory plaque or nodule, associated with pain and tenderness, localized on the site of a previous traumatic lesion (Figure 4); tumors, which

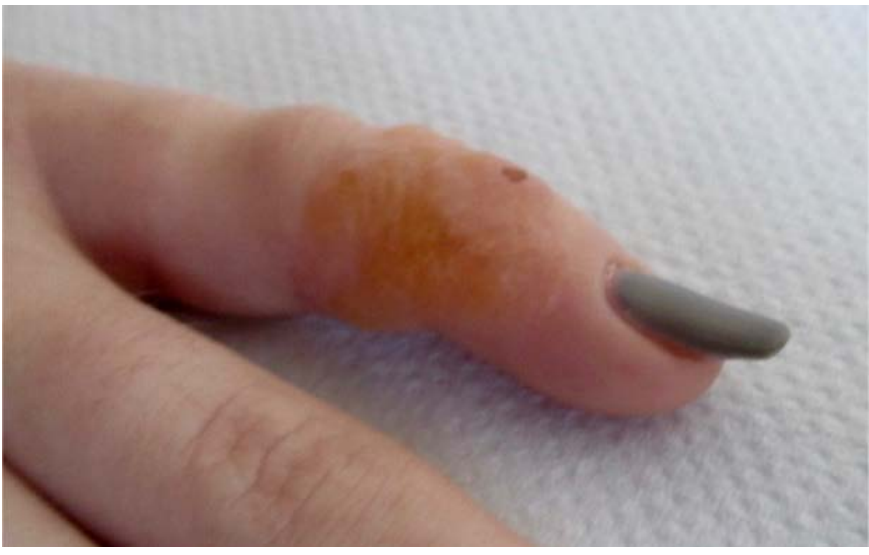

FIGURE 5. Tumoral lesion on the fifth left digit

are rarely reported on the fingers, and the diagnosis is certified by histopathological examination of the excised tumor (Figure 5); gottron papules - the hallmark sign of dermatomyositis, consisting of erythematous to violaceous papules and plaques over the extensor surfaces of the metacarpophalangeal and interphalangeal joints (Figure 6). Pseudo-knuckle pads are more frequently seen as calluses/callosities or hyperkeratotic lesions caused by repeated frictional trauma, chewing, and pressure, induced by the habit of finger chewing or sucking as an expression of psychiatric disorders (e.g., bulimia nervosa and self-induced vomiting, obsessive behavior), or are occupational skin diseases in patients who practice boxing or surfing. ${ }^{4}$ Pseudo-knuckle pads are mostly described in younger or middle-aged patients and have a different clinical aspect: erythematous, thickened, fixed plaques, sometimes associated with scales and superficial excoriations, located on the extensor surface of the first digit of one hand. Skin biopsy, rarely necessary, demonstrates acanthosis with overlying orthokeratosis and hyperkeratosis (Figure 7).

Laboratory tests are of great value for confirming the diagnosis of knuckle pads.
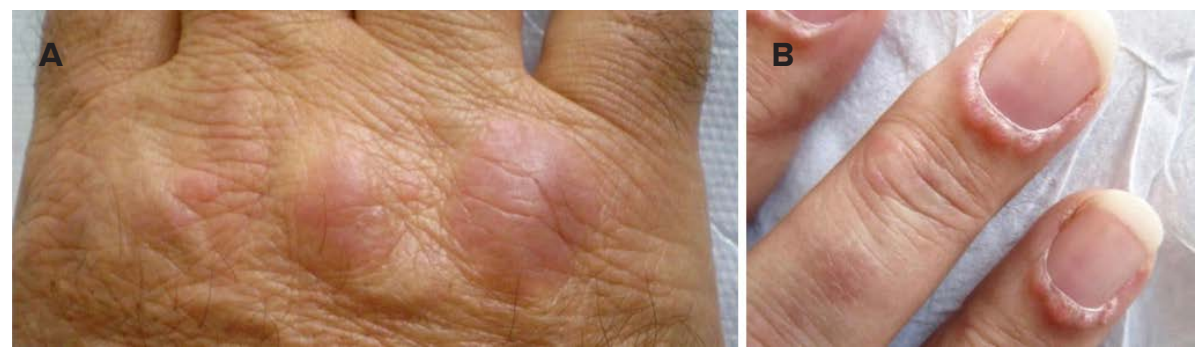

FIGURE 6. Gottron papules - erythemato-violaceus nodules over the extensor surfaces of metacarpophalangeal and interphalangeal joints, associated with similar lesions around the nails $(\mathbf{A}, \mathbf{B})$ 




FIGURE 7. Pseudo-knuckle pads in a patient with severe psychiatric disorder: erythematous, thickened, fixed plaques associated with scales and superficial excoriations on the dorsal aspect of the joints

Ultrasonography shows a hypoechoic structure above the tendons, certifying the diagnosis of knuckle pads and differentiating the lesion from different types of arthritis of the proximal interphalangeal joints. In case of foreign body granuloma, ultrasound is of great help showing the foreign body localized in the subcutis. Ultrasound examination, besides showing the thickening of the skin, can exclude bone and synovial involvement, but cannot be used in differentiating the real knuckle pads from pseudoknuckle pads.

Optical coherence tomography has been used as an investigative tool to demonstrate and quantify knuckle pads, ascertaining the absence of hair follicles and acrosyringium and the presence of white hyper-reflective zones that correspond to orthokeratosis. ${ }^{8}$

Skin biopsy is the investigation that formulates the differential diagnosis with disorders that can clinically mimic knuckle pads.

Psychiatric evaluation is necessary in case of pseudoknuckle pads; the recognition of pseudo-knuckle pads by the dermatologist or any other physician is very important, because these lesions may represent clues for a treatable severe psychiatric disorder.

Radiographic images of the interphalangeal joints and specific laboratory investigations could be necessary in ruling out disorders that can present in association with other resembling skin lesions on the hands.

\section{CONCLUSION}

The recognition of knuckle pads is important for orientating the diagnosis and treatment. Age, clinical features, associated diseases, laboratory and imaging investigations can greatly contribute to the diagnosis. Differential diagnosis is of outmost value excluding rheumatoid arthritis, dermatomyositis, post-traumatic foreign body granuloma, gouty tophi, or tumors; patients should be treated in different medical units. A clear distinction between knuckle pads and pseudo-knuckle pads must be also made, with consequences on practical clinical approach. Patients diagnosed with pseudo-knuckle pads should be referred to Occupational Medicine, or if a psychiatric disease is suspect to the Psychiatric Department. Diabetic patients who present finger pebbles and/or knuckle pads should be closely followed-up for metabolic disorders. In the case of real idiopathic knuckle pads, the patient's treatment and outcome is focused on the benign nature of the disease and simple daily-administered emollients are necessary.

\section{CONFLICT OF INTEREST}

The authors report no conflicts of interest in this work.

\section{ACKNOWLEDGEMENT}

Informed consent was obtained from the patients for the publication of the pictures.

\section{REFERENCES}

1. Garrod AE. On an unusual form of nodule upon the joints of the fingers. $\mathrm{Br}$ Med J. 1893;29:157-161.

2. Ronchese F. Knuckle pads and similar-looking disorders. Giorn Ital Derm 1966:107:1227-1236

3. Nenoff P, Woitek G. Images in clinical medicine. Knuckle pads. N Engl J Med. 2011;364:2451.

4. Huntley AC. Finger pebbles: a common finding in diabetes mellitus. J Am Acad Dermatol. 1986;14:612-617.

5. Kodama BF, Gentry RH, Fitzpatrick JE. Papules and plaques over the joint spaces. Knuckle pads (heloderma). Arch Dermatol. 1993;129:1044-1045.

6. Saylam Kurtipek G, Kutlu O, Duran C, Kurku H, Ataseven A, Tuncez Akyurek F. Frequency of metabolic syndrome in patients with knuckle pads. J Dermatol. 2015;42:1165-1168

7. Lautenschlager S, Itin PH, Rufli T. Pachydermodactyly: reflecting obsessivecompulsive behavior? Arch Dermatol. 1994;130:387.

8. Luber AJ, Bienenfeld AR, Clark CM, Markowitz O. Characterization of knuckle (Garrod) pads using optical coherence tomography in vivo. Cutis. 2015;96:E10-E11. 